\title{
Protecting women and girls from tobacco and alcohol promotion
}

\section{Gender transformative measures could curb the industries' expansion into low and middle income countries, contain the burden of chronic disease, and promote gender equity, argue Emma Feeny and colleagues}

W omen have traditionally consumed less tobacco and alcohol than men because social and cultural norms have stigmatised their use of these products, particularly in low and middle income countries. The combination of changing gender norms, aggressive industry marketing, and continuing population growth in low and middle income countries, however, means that without urgent action, the number of women and girls consuming tobacco and alcohol is likely to rise substantially in the coming years.

This change has important implications for the burden of chronic or noncommunicable diseases and injuries, for public health, service delivery, and-given the strong, reciprocal links between noncommunicable diseases and poverty ${ }^{1}-$ sustainable development. Consumption of tobacco and alcohol has repercussions

\section{KEY MESSAGES}

- Women and girls in low and middle income countries are exposed to aggressive marketing tactics by tobacco and alcohol industries, which exploit gender inequalities and associate their products with women's empowerment

- A rise in the consumption of alcohol and tobacco among women and girls will lead to an increase in non-communicable diseases globally, both in the short term and among generations to come

- A rise in non-communicable dieases has important implications for public health and the achievement of global development goals

- Governments and other stakeholders should tackle gender and other inequalities while improving health to protect women and girls in low and middle income countries from tobacco and alcohol promotion throughout life, particularly when it begins at a young age, making it harder to stop or reduce consumption later in life. Such consumption increases women's risk of developing cardiovascular diseases, cancers, and a range of other conditions (table 1). Risks can also be transmitted to the next generation: tobacco and alcohol use during pregnancy can have lasting effects on the health of children, who are also more likely to use tobacco and alcohol themselves if exposed to parental consumption. ${ }^{45}$

Non-communicable diseases already account for over $70 \%$ of all deaths worldwide, but this huge and growing burden among women is often overlooked by global health stakeholders, who continue to view women's health from a reproductive viewpoint. The biggest killers of women globally are cardiovascular diseases, cancers, and chronic respiratory diseases. ${ }^{6}$ People living with noncommunicable diseases are also at risk of severe covid-19 should they become infected. $^{7}$

Because tobacco and alcohol use are now steady or falling in many high income countries, producers have identified women and girls in low and middle income countries as a growing market. ${ }^{89}$ The global prevalence rates of smoking among women are decreasing, but trends among girls are concerning; in 123 countries, the prevalence of girls using tobacco is higher than the prevalence of adult women, and in some countries, such as Mozambique and Argentina, it is also higher than the prevalence of adolescent boys using tobacco. ${ }^{10}$ The proportion of men who drink is much higher than the proportion of women who do so, but the global gap between male and female drinkers is shrinking. ${ }^{11}$

These threats are well recognised, but calls for action to reduce the exposure of women and girls in low and middle income countries to the well honed tactics of the tobacco and alcohol industries have so far gone unheeded. ${ }^{912}$ If this continues, we can expect to pay a high price, with an increase in non-communicable diseases and undermining of hard won development gains. Developments in sex and gender research and practice provide opportunities to not only prevent a rise in smoking and drinking among girls and women, but to break down pervasive gender inequities while doing so. ${ }^{13}$

\section{Sex specific impacts of tobacco and alcohol, and interaction with gender}

To understand the association between women, tobacco, and alcohol, and bet-

\begin{tabular}{|c|c|c|}
\hline Risk factor & Women's health & In pregnancy \\
\hline Smoking & $\begin{array}{l}\text { - Cardiovascular disease, including coronary heart disease } \\
\text { and ischaemic stroke } \\
\text { - Cancers of the bladder; blood (acute myeloid } \\
\text { leukaemia); cervix; colon and rectum; oesophagus and } \\
\text { larynx; kidney and renal pelvis; liver; lungs, bronchi, and } \\
\text { trachea; mouth and throat; pancreas; and stomach } \\
\text { - Type } 2 \text { diabetes } \\
\text { - Chronic obstructive pulmonary disease } \\
\text { - Infertility } \\
\text { - Lower bone density and hip fracture among postmeno- } \\
\text { pausal women }\end{array}$ & $\begin{array}{l}\text { - Lower birth weight } \\
\text { - Stillbirth } \\
\text { - Neonatal death } \\
\text { - Sudden infant death syndrome } \\
\text { - Possible reduction in breast milk }\end{array}$ \\
\hline Alcohol & $\begin{array}{l}\text { - Cirrhosis and other alcohol related liver diseases } \\
\text { - Damage to the brain } \\
\text { - Diseases of the heart muscle } \\
\text { - Cancers of the mouth, throat, oesophagus, liver, colon, } \\
\text { and breast } \\
\text { - Unintentional injuries, such as road traffic injuries, } \\
\text { drowning, and falls }\end{array}$ & $\begin{array}{l}\text { - Miscarriage } \\
\text { - Stillbirth and premature delivery } \\
\text { - Intrauterine growth retardation } \\
\text { - Low birth weight } \\
\text { - Having a baby with fetal alcohol } \\
\text { - spectrum disorder } \\
\text { - Sudden infant death syndrome }\end{array}$ \\
\hline
\end{tabular}


ter protect women and girls from tobacco and alcohol promotion, it is important to distinguish between sex-the biological attributes that distinguish male, female, and intersex; and gender-the social and cultural norms, identities, and relations that structure societies and shape our attitudes and behaviour. ${ }^{14}$

Sex specific factors, such as hormones, genetics, anatomy, physiology, and organ function, affect our response to tobacco and alcohol, and so rates of intoxication, dependency, or damage. For example, women typically have a higher proportion of body fat and water and fewer enzymes to metabolise alcohol. ${ }^{14}$ Similarly, differences in the way in which male and female bodies respond to nicotine, which are linked to sex hormones, might help to explain why fewer women quit smoking. ${ }^{15}$

Increasing research is disclosing how sex specific factors can also affect health conditions linked with alcohol and tobacco consumption, and so prevalence of noncommunicable diseases. For example, alcohol seems to have greater long term negative effects on the health of women than on men, including liver problems, diseases of the heart muscle, and cognitive dysfunction. ${ }^{16}$ Smoking has effects that are specific to women, such as cervical and breast cancer, and appears to increase the risk of some diseases more in women than in men-for example, coronary heart disease. $^{17}$

A complex interaction is found between sex specific factors and gendered attitudes, behaviours, and relations. For example, in many contexts, gender norms attach particular stigma to women's consumption of tobacco and alcohol, which might prevent them from seeking support to quit. Women experience high rates of intimate partner and sexual violence, which is often linked to alcohol consumption among men, but can trigger "victim blaming" of women if they have also been drinking. Gender ideals of slimness can see women take up smoking as an aid to weight loss.

Sex and gender also intersect with a range of equity based factors, including age, sexuality, income level, and ethnicity. For example, in some contexts, smoking is more prevalent among women experiencing poverty, while sexual minority status-being gay, lesbian, bisexual, or pansexual-is a risk factor for higher prevalence of substance use in general. ${ }^{14}$

In this paper we focus on industry's targeting of women and girls in low and middle income countries as potential consumers of tobacco and alcohol. We do not cover other important matters related to sex and gender, such as exposure of women and girls to secondhand smoke and to interpersonal violence linked to men's use of alcohol.

\section{Exploiting gender narratives around women's empowerment}

When women are regularly confronted with gender power imbalances which limit their opportunities and choices, a vision of equality can be appealing. Tobacco and alcohol companies have exploited this effectively, using gendered marketing that links alcohol and tobacco with female empowerment and other aspirations. ${ }^{18} 19$ An analysis of alcohol marketing in India and a number of African countries, for example, found that women were targeted through associations with empowerment, Western lifestyles, wealth, and sexual success. ${ }^{19}$ Similarly, the tobacco industry has used images of the cigarette as a "torch of freedom" for women as it creates new markets around the world. ${ }^{18}$

In line with other advertising targeting women, the tobacco and alcohol industries use numerous, often contradictory, gendered norms and behaviours in their quest to attract new consumers. While the narrative is one of female empowerment, it is often underpinned by a hypersexualised portrayal of women's bodies and the use of gender stereotypes, such as a preference for sweeter flavours, or desire to conform to a feminine ideal ${ }^{19}$ (box 1).

Despite reinforcing gender stereotypes and inequalities through their traditional marketing techniques, both tobacco and alcohol brands have used corporate social responsibility initiatives to associate themselves with gender equity campaigns and empowerment projects in low and middle income countries. One global alcohol company has partnered with an international non-government organisation to "empower women and engage men to address the root causes of gender inequality through research, programming, and advocacy activities." 20 The same brand's activities in India have included a programme to empower women through education and work skills. ${ }^{19}$ Initiatives ostensibly focused on gender equity have also been implemented during the covid19 pandemic. For example, in South Africa, one alcohol company launched a WhatsApp helpline in response to a sharp rise in gender based violence during national lockdown. ${ }^{21}$

These companies have a wealth of experience to draw on, as the unhealthy commodity industries-tobacco, alcohol, food, and beverages-use similar and shared strategies to promote products detrimental to health; one of the definitions of "the commercial determinants of health." 22 There is a well-documented history of these industries infiltrating public health organisations, subverting science, and undermining public health policies ${ }^{23}$; including non-communicable disease control measures during the covid19 pandemic. $^{24}$

\section{Blocking the path to progress}

One of the core obstacles to dealing with industry tactics is the idea that governments should let individuals make their own choices; a naïve concept given that individual choices are influenced by factors including context, education, and availability of alternatives. ${ }^{25}$ Governments should implement policies to facilitate healthier lives for all their citizens, but are

Box 1: Slim, pink, and fruity: marketing tobacco and alcohol to women and girls in low and middle income countries ${ }^{919}$

Using their experience of successful marketing in high income countries, the tobacco and alcohol industries create products for low and middle income countries which are linked to narratives of empowerment, but based on gender norms and stereotypes. These products may be:

- Packaged in "feminine" colours (eg, pink, purple, glittery, or with a floral design), shapes (eg, purses), and sizes (eg, lipstick shaped boxes of cigarettes)

- Provided in different flavours-for example, drinks might be sweeter or fruit flavoured with lower alcohol content, cigarettes might be "light" or menthol

- Linked to messages about weight control-for example, "slim” cigarettes

- Linked to messaging about health-for example, beer as a way of improving skin and general beauty, or as a way of treating menstrual pain

- Promoted through media with a predominantly female audience-for example, women's magazines

- Given away, discounted, or sold cheaply, with home delivery offered in some cases where cultural norms deter women from making purchases 
too often hindered by conflicts of interest, or face aggressive lobbying by industry.

Another challenge is double standards, which mean that-in contrast to the imagery of industry driven marketing campaigns-women who drink or smoke are more likely than men to be portrayed negatively in news reports and other media coverage. ${ }^{26}$ These double standards mean that control policies and public health messaging targeting women have a stigmatising and punitive effect in some circumstances, particularly for pregnant women and mothers. ${ }^{27}$

Robust surveillance and monitoring of tobacco and alcohol consumption at a country level is often lacking, ${ }^{28}$ and the gendered approach of industry contrasts starkly with the limited extent to which control and research communities apply gender and diversity based analyses. ${ }^{9}$ Sex and gender have largely been missing from research and control of substance use, ${ }^{14}$ and arguably from non-communicable disease prevention measures in general, despite the commitments to pursue and promote gender based approaches made by governments at the first UN high level meeting on noncommunicable diseases in 2011. ${ }^{29}$ All stakeholders urgently need to catch up with industry, and focus on the gaps in evidence which persist for women and girls in low and middle income countries.

\section{Adopting a gender transformative approach to counter industry tactics}

A gender transformative approach recognises gender as a key determinant of health and aims to tackle the causes of inequalities by transforming harmful gender roles, norms, and relations, while improving health. ${ }^{13}$ Growing evidence in the fields of HIV and violence against women suggests this approach might offer a more effective framework for alcohol and tobacco prevention, and treatment programmes to counter gendered industry tactics.

Examples of gender transformative programmes are scarce and come mostly from high income countries. These programmes, however, offer promise for low and middle income countries because they seek to tackle the gender inequalities that leave women and girls exposed to industry tactics. For example, one US intervention focused on 12-13 year old girls and their relationships with their mothers. The intervention built the girls' agency by promoting their social skills and decision making as ways of coping with stress, managing substance use, questioning peer norms, and understanding media influences, while their mothers were supported to improve their rule setting and monitoring of substance use. The programme changed normative beliefs, reduced substance use among the girls, and reduced alcohol consumption among their mothers. ${ }^{30}$

Interventions to deal with alcohol consumption on college campuses in Canada have included peer run programmes to promote examination of, and change in, the gender norms and inequities that underlie alcohol use to reduce consumption and promote health. In doing so the programmes work to empower women to question the alcohol industry's gendered marketing approaches. ${ }^{31}$

Introducing a gender transformative approach in low and middle income countries to counter tobacco and alcohol promotion will require action by a range of stakeholders beyond those in the health promotion sector. To increase governments' motivation to act-and their accountability-the approach can be aligned with other rights based mechanisms to achieve gender equality and promote health and wellbeing according to the sustainable development goals. ${ }^{32}$

Civil society stakeholders and grassroots movements play an important part in raising awareness of the effects on health of tobacco and alcohol. They also highlight the harmful use of gender stereotypes in marketing and sponsorship campaigns, and the extent of industry interference in policy making. For example, the International Network of Women Against Tobacco, which was founded in 1990, seeks to improve women's health and increase gender equality by sharing information and strategies on countering tobacco promotion, supporting women centred prevention and cessation programmes, and promoting female leadership. ${ }^{33}$

Civil society can also use public health laws and human rights frameworks to require governments to deal with industry tactics and increase gender equality. For example, local groups led by the InterAmerican Heart Foundation of Argentina submitted a shadow report to the UN Committee on the Elimination of all forms of Discrimination Against Women (CEDAW) in 2016. The report called for the committee to recommend that the government of Argentina ban all forms of advertising, promotion, and sponsorship of tobacco products according to World Health Organization Framework Convention on Tobacco Control (FCTC) ${ }^{34}$ standards to prevent the tobacco industry from targeting women and girls. ${ }^{35}$ The committee did subsequently make this recommendation.

While the government of Argentina has yet to do so, it is imperative that countries meet their commitments under CEDAW and FCTC. They should also follow the recommendations set out in WHO frameworks such as the 2010 Global Strategy to Reduce the Harmful Use of Alcohol, and technical packages, including MPOWER for tobacco and SAFER for alcohol. These packages include not only bans and comprehensive restrictions on advertising, promotion, and sponsorship, but also the collection of sex disaggregated surveillance and monitoring data, and the full participation of women at all levels of policy making and implementation. ${ }^{3436-38}$ Multilateral and human rights agencies should support governments to meet their commitments and hold them to account when they fail to do so.

Finally, researchers should focus on the gaps in evidence that persist on alcohol and tobacco consumption among women and girls in low and middle income countries, and investigate strategies to counter industry campaigns. To design effective interventions, multidisciplinary research is needed into how sex specific factors and gender interact, and intersect with age, class, ethnicity, religion, education, identity, poverty, and other factors to make women and girls more or less vulnerable to alcohol and tobacco marketing. Research funders can support this by providing grants to mobilise knowledge and identify best practice examples of gender transformative approaches to health promotion, prevention, cessation, and treatment programmes.

\section{Win-win on non-communicable diseases and gender equity}

Based on 2010-16 trends, women in just 17 of 176 countries (and men in only 15 countries) are expected to achieve sustainable development goal target 3.4-namely, reduction by a third relative to 2015 levels of the probability of dying from a non-communicable disease between the ages of 30 and $70 .{ }^{39}$ The time for discussion has long gone. We have an opportunity to shift the focus from individual behaviours to government action, recognising and dealing with the broader inequalities that underlie the consumption of alcohol and tobacco and are exploited by industry. Such a gender transformative approach offers promise not only for sustainable development goal target 3.4, but for target 5-that is, to achieve gender equality and empower all women and girls. 
We thank Avni Amin and Michelle Remme for their support and advice. We appreciate inputs from Maisha Hutton at the Healthy Caribbean Coalition: Lucy Westerman at the Non-Communicable Disease Alliance; and Vinayak M Prasad at the No Tobacco unit in WHO's health promotion department.

Contributors and sources:EF, CV, and KD led the conceptualisation with advice from Avni Amin. EF led the drafting of the paper with input from CV, KD, and GAA. DR and HNG provided expert contributions on alcohol and tobacco, respectively. The authors are advocates, researchers, and technical officers engaged in various ways with non-communicable diseases and their determinants, and drew on their collective experience and knowledge of the literature.

Competing interests: We have read and understood BMJ policy on declaration of interests and have no interests to declare. The views expressed are solely the responsibility of the authors and do not necessarily reflect the views, decisions, or policies of the institutions with which they are affiliated.

Provenance and peer review: Commissioned; externally peer reviewed.

This article is part of a series commissioned by The $B M$ J based on an idea from the United Nations University-International Institute for Global Health and the World Health Organization to mark the 25th anniversary of the adoption of the 1995 Beijing Platform for Action. The BMJ retained full editorial control over external peer review, editing, and publication. WHO and UNU-IIGH paid the open access fees.

Emma Feeny, advocacy director ${ }^{1}$

Katie Dain, chief executive officer ${ }^{2}$

Cherian Varghese, cross-cutting lead, NCDs and special initiatives $^{3}$

George A Atiim, researcher ${ }^{4}$

Dag Rekve, senior technical officer ${ }^{3}$

Hebe N Gouda, project officer ${ }^{3,5}$

${ }^{1}$ The George Institute for Global Health, United Kingdom ${ }^{2} \mathrm{NCD}$ Alliance, Switzerland

${ }^{3}$ World Health Organization, Switzerland

${ }^{4}$ United Nations University-International Institute for Global Health, Malaysia

${ }^{5}$ School of Public Health, University of Queensland

Correspondence to: E Feeny

efeeny@georgeinstitute.org

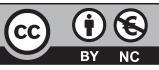

This is an Open Access article distributed under the terms of the Creative Commons Attribution IGO License (https://creativecommons.org/licenses/ by-nc/3.0/igo/), which permits use, distribution, and reproduction for non-commercial purposes in any medium, provided the original work is properly cited.

\section{Check for updates}

1 Nugent R, Bertram MY, Jan S, et al. Investing in noncommunicable disease prevention and management to advance the sustainable development goals. Lancet 2018;391:2029-35. doi:10.1016/S01406736(18)30667-6

2 Centers for Disease Control and Prevention. Excessive alcohol use and risks to women's health. 2019. https://www.cdc.gov/alcohol/fact-sheets/womenshealth.htm

3 Centers for Disease Control and Prevention. Tobacco and cancer. https://www.cdc.gov/cancer/tobacco/ index.htm
4 Yap MBH, Cheong TWK, Zaravinos-Tsakos F, Lubman DI, Jorm AF. Modifiable parenting factors associated with adolescent alcohol misuse: a systematic review and meta-analysis of longitudinal studies. Addiction 2017;112:1142-62. doi:10.1111/ add. 13785

5 Wellman RJ, Dugas EN, Dutczak $\mathrm{H}$, et al. Predictors of the onset of cigarette smoking: a systematic review of longitudinal population-based studies in youth. Am J Prev Med 2016;51:767-78. doi:10.1016/j. amepre.2016.04.003

6 IHME. GBD compare. Viz hub 2020. https://vizhub. healthdata.org/gbd-compare/

7 The Lancet. COVID-19: a new lens for noncommunicable diseases. Lancet 2020;396:649. doi:10.1016/S0140-6736(20)31856-0

8 NCD Alliance, Global Alcohol Policy Alliance, Healthy Latin America Coalition, Healthy Caribbean Coalition. The alcohol industry's commercial and political activities in Latin America and the Caribbean-implications for public health. 2020. https://ncdalliance.org/resources/thealcohol-industry\%E2\%80\%99s-commercial-andpolitical-activities-in-latin-america-and-caribbeanimplications-for-public-health

9 Amos A, Greaves L, Nichter M, Bloch M. Women and tobacco: a call for including gender in tobacco control research, policy and practice. Tob Control 2012;21:236-43. doi:10.1136/ tobaccocontrol-2011-050280

10 Maitin-Shepard M, Carlyle RC, Shaikh S. Tobacco industry targets women and girls as next generation of smokers. Tobacco Atlas. 2020. https:// tobaccoatlas.org/2020/04/07/female-targets/

11 Manthey J, Shield KD, Rylett M, Hasan OSM, Probst C, Rehm J. Global alcohol exposure between 1990 and 2017 and forecasts until 2030: a modelling study. Lancet 2019;393:2493-502. doi:10.1016/S01406736(18)32744-2

12 World Health Organization and Pan-American Health Organization. Gender, health and alcohol use. World Health Organization, 2005.

13 Pederson A, Greaves L, Poole N. Gendertransformative health promotion for women: a framework for action. Health Promot Int 2015;30:140-50. doi:10.1093/heapro/dau083

14 Greaves L. Missing in action: sex and gender in substance use research. Int J Environ Res Public Health 2020;17:2352. doi:10.3390/ ijerph17072352.

15 Pogun S, Yararbas G. Sex differences in nicotine action. In: Henningfield JE, London ED, Pogun S, eds. Nicotine psychopharmacology. Springer, 2009:26191. doi:10.1007/978-3-540-69248-5_10

16 Erol A, Karpyak VM. Sex and gender-related differences in alcohol use and its consequences: contemporary knowledge and future research considerations. Drug Alcohol Depend 2015;156:113. doi:10.1016/j.drugalcdep.2015.08.023.

17 Huxley RR, Woodward M. Cigarette smoking as a risk factor for coronary heart disease in women compared with men: a systematic review and meta-analysis of prospective cohort studies. Lancet 2011;378:1297305. doi:10.1016/S0140-6736(11)60781-2

18 Amos A, Haglund M. From social taboo to "torch of freedom": the marketing of cigarettes to women. Tob Control 2000;9:3-8. doi:10.1136/tc.9.1.3

19 Atkinson AM, Sumnall H, Begley E, Jones L. A rapid narrative review of literature on gendered alcohol marketing. Institute of Alcohol Studies, 2019. https:// www.ias.org.uk/wp-content/uploads/2020/06/ rp39102019.pdf

20 Care International UK. CARE and Diageo: a global value chain approach to promoting women's empowerment. 2021. https://www.careinternational. org.uk/get-involved/corporate-partnerships/who-wework-with/Diageo

21 Collin J, Ralston R, Hill S, Westerman L. Signalling virtue, promoting harm - unhealthy commodity industries and COVID-19. NCD Alliance \& SPECTRUM,
2020. https://ncdalliance.org/sites/default/files/ resource_files/Signalling\%20Virtue\%2C\%20 Promoting\%20Harm_Sept2020_FINALv.pdf

22 Kickbusch I, Allen L, Franz C. The commercia determinants of health. Lancet Glob Health 2016;4:e895-6. doi:10.1016/S2214109X(16)30217-0

23 Collin J, Hill S. Structure and tactics of the tobacco, alcohol, and sugary beverage industries: background brief prepared for the Task Force on Fiscal Policy for Health. Bloomberg, 2019. https://data.bloomberglp. com/dotorg/sites/2/2019/04/Health-Taxes-toSave-Lives-Briefs.pdf

24 STOP. The tobacco industry's subversive lobbying during COVID-19. STOP. 2020. https:// exposetobacco.org/news/ti-subversive-lobbying/

25 GBD 2019 Viewpoint Collaborators. Five insights from the Global Burden of Disease Study 2019. Lancet 2020;396:1135-59. doi:10.1016/S01406736(20)31404-5

26 Institute of Alcohol Studies. Women and alcohol: key issues. Institute of Alcohol Studies, 2018. https:// www.ias.org.uk/report/women-and-alcohol-keyissues/

27 Burgess DJ, Fu SS, van Ryn M. Potential unintended consequences of tobacco-control policies on mothers who smoke: a review of the literature. Am J Prev Med 2009;37(Suppl):S151-8. doi:10.1016/j. amepre.2009.05.006

28 World Health Organization. WHO report on the global tobacco epidemic. World Health Organization, 2019. https://apps.who.int/tobacco/global_report/en/

29 United Nations General Assembly. Political declaration of the high-level meeting of the general assembly on the prevention and control of noncommunicable diseases: draft resolution/submitted by the president of the general assembly. 2011. https://digitallibrary.un.org/record/710899/

30 Stinson J, Wolfson L, Poole N. Technology-based substance use interventions: opportunities for gender-transformative health promotion. Int J Environ Res Public Health 2020;17:992. doi:10.3390/ ijerph17030992

31 Wolfson L, Stinson J, Poole N. Gender informed or gender ignored? Opportunities for gender transformative approaches in brief alcohol interventions on college campuses. Int J Environ Res Public Health 2020;17:396. doi:10.3390/ ijerph17020396

32 Hawkes S, Buse K. Gender-responsive tobacco control: evidence and options for policies and programmes. World Health Organization, 2018. https://www.who.int/fctc/cop/sessions/cop8/ Gender-Responsive-Tobacco-Control.pdf

33 International Network of Women Against Tobacco. Our work. 2021. https://inwat.org/our-work/

34 World Health Organization. WHO Framework Convention on Tobacco Control. 2003. http://apps.who.int/iris/bitstream/ handle/10665/42811/9241591013. pdf?sequence $=1$

35 Fundación Interamericana del Corazon Argentina. Shadow report to the periodic report by the Government of Argentina-challenges in the prevention and reduction of women's tobacco use in Argentina. Fundación Interamericana del Corazon Argentina, 2016.

36 World Health Organization. MPOWER. 2020. https:// www.who.int/initiatives/mpower

37 World Health Organization. The SAFER initiative. 2020. https://www.who.int/initiatives/SAFER

38 World Health Organization. Global strategy to reduce the harmful use of alcohol. WHO, 2010

39 NCD Countdown 2030 collaborators. NCD Countdown 2030: pathways to achieving sustainable development goal target 3.4. Lancet 2020;396:91834. doi:10.1016/S0140-6736(20)31761-X

Cite this as: BMJ 2021;374:n1516

http://dx.doi.org/10.1136/bmj.n1516 